\title{
Oil Sector Spillover Effects to the Kuwait Stock Market under Uncertainty
}

\author{
Yousef M. Abdulrazaq \\ Assistant Professor of Finance \\ Department of Economics and Finance \\ Gulf University for Science and Technology, Kuwait \\ E-mail: abdulrazaq.y@gust.edu.kw \\ Shekar Shetty \\ Associate Professor of Finance \\ Department of Economics and Finance \\ Gulf University for Science and Technology, Kuwait \\ E-mail: shetty.s@gust.edu.kw
}

\begin{abstract}
The purpose of this paper is to identify the connection between oil prices and the performance of oil and gas, industry and services sectors. The paper is supported by the granger causality and Engle and Granger cointegration tests. The research findings do not support a long-run association between Brent oil prices excluding the case of the Oil and Gas sector index; however, short-run dynamics were recognized. There is no unidirectional causality found in any case. The outcomes of the GARCH model show stable results for all three sectors.
\end{abstract}

Keywords: Kuwait, Stock Market, Oil Prices, Market Uncertainty, Causality, Volatility.

\section{Introduction}

In recent years, literature has been dedicated to oil prices affecting macroeconomic factors in developed nations (Killian, 2009). Among the existing literature, attention is being focused on interlinkage among oil prices and stock markets. Besides that there is no theoretical pattern that characterizes the interlinkage between the financial markets and oil, empirical research reveals that instability in oil prices impact firms' performance, cost, and incomes, which thereafter impact stock market returns. Most of the literature has information on the interlinkage between the oil and equity markets in oil-dependent economies, like the united states (US), where raise in oil prices have unfavorable economic impacts. When oil price boosts, oil-importing economies can experience heavy negative results and economic recession (Federer, 1996). However, the impression of oil prices on oil-rich countries is different, a surge in oil prices recovers the balance of trade, causing a greater current account surplus, and an upgrading foreign asset position (Abdelaziz et al., 2008). For this reason, this paper investigates the affiliation between equity markets and oil prices from the perspective of oil-exporting countries such as Kuwait.

Kuwait is considered to be one of the main oil exporters on world energy markets, and the variation in equity returns on Kuwait's stock markets is likely to be sensitive to differences in oil prices. Also, Kuwait's stock markets are prone to regional political events that separate them from developed and emerging markets. The recent global trend of rising oil prices is bringing more cash flows to Kuwait, which is having a positive effect on stock market listed sectors. Consequently, recognizing shifts in oil prices on Kuwait's stock market returns at the sectoral level allows investors to make more focused investment choices and to provide new evidence for policymakers monitoring stock markets. As such, a study involving the Kuwait stock market and the stock index at the sectoral level should be of great interest.

The interlinkage between oil prices and equity market behavior has enjoyed a considerable level of attention among the researchers (Arezki et al., 2017; Al-Qudsi \& Ali, 2016; Guesmi et al., 2018) debate that the fluctuation of oil prices is a risk factor causing market contagion towards stock markets with origins on oil price volatility. Oil prices can impact equity markets through various methods, as rising oil prices can boost interest rates lead to control inflationary pressures, increase inputs costs which will reduce gains that affect negatively on the stock returns (Jiang et al., 2017; Grima \& Caruana, 2017; Adrangi et al., 2014; Ansani \& Daniele, 2012; Filis et al., 20II). Narayan \& Gupta (2015) used the least square estimation and utilizing monthly data for I50 years and their result in favor of nonlinear likelihood, proposing that inverse oil prices predict US stock return. Cunado \& de Gracia (2014) confirmed the influence oil prices shocks on 12 oil-dependent European countries (Belgium, Austria, Finland, Denmark, Germany, France, Italy, Luxembourg, Spain, Portugal, the Netherlands, and the UK). They used monthly data for the period from February 1973 to December 20I I. The outcome has shown that oil price changes in 
Belgium, Denmark, Finland, France, Italy, Luxembourg, the Netherlands, Portugal, Spain, and the United Kingdom have a significant negative impact on stock returns, as regards to the global oil price. Narayan \& Sharma (20I4) investigated the oil price fluctuation that impacts the stock returns. They utilized daily returns of 560 listed firms on the Stock Exchange (New York), and they were separated into I4 sub-sectors. The outcomes reveal that the fluctuation in oil price impacts a firm's returns differently based on their sectors. Azar \& Basmajian (2013) used three types of non-linearity to analyze the effect of the price of oil shocks on the stock markets of the two largest and most liquid GCC equity markets, Kuwait and Saudi Arabia. The study found that oil price shocks do not affect the Kuwaiti stock market, either linearly or non-linearly, while the Saudi market non-linearly reacts to oil price variations in the US S \& P 500. Kumar \& Maheswaran (2013) explored if oil price instability has an impact on the Indian stock market's indices on a sectoral - like financial, metal and commodities, services and industry. The result showed that the industrial sector returns are directly impacted by oil price fluctuations.

\section{Methodology and Models Selection}

Various econometric models were implemented to test the interlinkage among oil prices and the following sector indexes of the Kuwaiti equity market: Oil and Gas, Industry and Services. Daily data of prices (Brent) were gathered from Energy Information Administration- EIA (USA) and stock prices were obtained from the Kuwait stock market over the period from January 2012 to December 2017. stock prices are converted into returns by using natural logarithms $-S R_{t}=\ln \left(S P_{t}\right)-\ln \left(S P_{t-1}\right)$; similarly, Brent oil prices are also transformed into returns

$B R_{t}=\ln \left(B P_{t}\right)-\ln \left(B P_{t-1}\right)$

Where

$S R=$ stock return

$S P=$ stock price

$B R=$ Brent oil returns

$B P=$ Brent oil price

\section{I Preliminary Tests}

A vector autoregressive (VAR) framework was implemented to ensure choosing the optimum number of lags in econometric modeling. The method of lag selection is important and needs attention because the use of lags might have a direct influence on the estimation progression. On the other side, a small number of lags can lead to autocorrelation in the model. Also, a lengthier lag increases the size of the parameter affecting the degree of freedom that raises massive issues about the estimated model (Ivanov \& Kilian, 2005).

The ADF test was implemented based on the equation given below:

$$
\Delta y_{t}=\beta_{1}+\beta_{2} t+\delta y_{t-1}+\alpha_{i} \sum_{t=1}^{m} \Delta y_{t-1}+\varepsilon_{t}
$$

To cross-check the results of the ADF method, the Phillips and Perron (PP) test, alike to the ADF test, but adding an automated amendment of the DF protocol to enable correlated error named as the Kwiatkowski - Phillips - Schmidt Shin test, which makes a null hypothesis, arguing that an obvious time series is smooth around a deterministic pattern. Three stationarity tests were considered for robustness purposes and due to significant levels of criticism associated with the performance of the ADF test.

\subsection{Testing For Long-Run Dynamics}

Two cointegration techniques (Johansen-Juselius and Engle-Granger) were used to test the presence of long-run testing among oil prices and Kuwait stock prices. The literature in the field informed the selection of the cointegration techniques with studies investigating the long-run association among stock markets and oil prices with an interest in the GCC nations (Bouri et al., 2016; Chau et al., 2014; Imarhiagbe, 2010; Miller \& Ratti, 2009; Arouri \& Fouquau, 2009; Granger et al., 2000). Other researchers have developed studies testing cointegration among stock prices and oil prices in a broader context, like, for example (Muhtaseb \& Al-Assaf, 2017; Bahmani-Oskooee \& Saha, 20I5; Asteriou \& Bashmakova, 20I3; Constantinos et al., 2010). These researches offer new evidence on the significance of the specific econometric models, and as such, they contribute to ensuring that the selected research framework to support this study is appropriate. Engle \& Granger (I987) endorse a two-step process for cointegration study that involves the estimation equation of the base-line equation listed below:

$$
y_{t}=\beta_{0}+\beta_{1} x_{t}+\mu_{t}
$$


The OLS residuals from the equation above are a measure of disequilibrium

$\hat{\mu}_{t}=y_{t}-\hat{\beta}_{0}-\hat{\beta}_{1} x_{t}$, where $\hat{\mu}_{t}$ is tested for stationarity.

The baseline of the Johansen and Juselius (JJ) (I990) test is as follows:

$\Delta \mathrm{Z}_{\mathrm{i}}=\alpha+\tau_{1} \Delta \mathrm{Z}_{\mathrm{t}-1}+\tau_{2} \Delta \mathrm{Z}_{\mathrm{t}-2}+\cdots+\tau_{\mathrm{k}-1} \Delta \mathrm{Z}_{\mathrm{t}-\mathrm{k}-1}+\pi_{\mathrm{k}} \mathrm{Z}_{\mathrm{t}-\mathrm{k}}+\mu_{\mathrm{t}}$

Where $Z_{t}$ and $\mu_{t}$ are explained as ( $\mathrm{m} x I$ ) vectors. The Johansen (I988) approach includes the estimation of eq. 4 and the analysis of the rank of matrix $P_{k}$. Precisely, if rank $\left(P_{k}\right)$ is equal to 0 , there will be no stationary linear grouping of variables in $\mathrm{Zt}$, there is no cointegration of the predictors. Since the matrix rank is a non-zero number of Eigenvalues (r), the quantity of the variables representing the number of cointegrating vectors. Two cointegration techniques were considered to allow cross-checking of the research outcomes.

\subsection{Testing For Short-Run Dynamics}

Granger causality uses linear prediction to determine if some event occurs before another (i.e., if we find Granger causality in one way only). The traditional Granger test was applied to understand if there is a sign of a pivotal link among the variables in a static dimension. To bring a dynamic dimension to the study, the causality frequency domain was considered to help to examine frequency-varying causal effects. Breitung \& Candelon's (2006) study is centered on previous work by (Hosoya, I99I; Geweke, 1982) that measured the vector comprising of $Y_{t}$ and $X_{t}$ with a finite-order of VAR characteristic of order $\mathrm{p}$. A brief insight into the test is presented below.

$\Theta(\mathrm{L})\left(\begin{array}{c}Y_{t} \\ X_{t}\end{array}\right)=\left(\begin{array}{ll}\Theta_{11}(L) & \Theta_{12}(L) \\ \Theta_{21}(\mathrm{~L}) & \Theta_{22}(L)\end{array}\right)\left(\begin{array}{c}Y_{t} \\ X_{t}\end{array}\right)=\varepsilon_{t}$

Where $\Theta(L)=I-\Theta_{1} L-\cdots-\Theta_{p} L_{p}$ is a $2 \times 2$ lag polynomial and $\Theta_{1}, \ldots, \Theta_{p}$ are $2 \times 2$ autoregressive parameter matrices, with $L^{k} X_{t}=X_{t-k}$ and $L^{k} Y_{t}=Y_{t-k}$. The error vector $\varepsilon_{t}$ is white noise with zero mean and $E\left(\varepsilon_{t} \varepsilon_{t}^{t}\right)=\Sigma$, where $\sum_{\text {is }}$ positive and finite. The MA representative of the system is

$\left(\begin{array}{l}Y_{t} \\ X_{t}\end{array}\right)=\psi(L) \eta_{t}=\left(\begin{array}{ll}\psi_{11}(L) & \psi_{12}(L) \\ \psi_{21}(L) & \psi_{22}(L)\end{array}\right)\left(\begin{array}{l}\eta_{1 t} \\ \eta_{2 t}\end{array}\right)$

With $\psi(L) \eta_{t}=\Theta(L)^{-1} G^{-1}$ and $\mathrm{G}$ is the lower triangular matrix of the Cholesky decomposition $G^{\prime} G=\Sigma^{-1}$ such that $E\left(\eta_{t} \eta_{t}^{\prime}\right)=I$ and $\eta_{t}=G \varepsilon_{t}$. The causality test developed by Geweke (I982) can then be written as:

$M_{X \Rightarrow \gamma}(\Upsilon)=\log \left[1+\frac{\left|\psi_{12}\left(e^{-i \gamma}\right)\right|^{2}}{\left|\psi_{11}\left(e^{-i \gamma}\right)\right|^{2}}\right]$

Within this outline no causality from $X_{t}$ to $Y_{t}$ at frequency $\gamma$ tallies to the condition $\left|\psi_{12}\left(e^{-i \gamma}\right)\right|^{2}=0$. Breitung and Candelon's (2006) main contribution is to demonstrate that this situation leads to

$\left|\Theta_{12}\left(e^{-i \gamma}\right)\right|=\left|\sum_{k=1}^{p} \Theta_{k, 12} \cos (k \gamma)\right|-i \sum_{k=1}^{p} \Theta_{k, 12} \sin (k \gamma) \mid=0$,

Where, $\Theta_{k, 12}$ is the $(\mathrm{I}, 2)$ the element of $\Theta_{k}$, such that a sufficient set of conditions for no causality is given by

$\sum_{k=1}^{p} \Theta_{k, 12} \cos (k \gamma) \mid=0$ and $\sum_{k=1}^{p} \Theta_{k, 12} \sin (k \gamma)=0$

Consequently, it is possible to test the null-hypothesis showing no Granger causality at the frequency $\pi$ using the generic F-test for the linear restriction imposed by the VAR member of order $p$, that tracks the distribution of $F(2$, T-2p) for each $\pi$, where $T$ represents numbers of series (Breitung \& Candelon, 2006). The selected methodological framework helped to identify the existence of long and short-run dynamics among oil prices (Brent Index) and the Kuwait Stock Exchange (KSE) by using well-known and established econometric models. 


\subsection{Volatility Measurement}

Variant prices, as well as stock trading fluctuations, are recognized as financial market uncertainty. The biggest concern about volatility is the decline in market trading (Ibbotson, 20II). To understand market risk, understanding of volatility is very important. Current research uses data on returns on the stock exchange that are deliberated more volatile and vulnerable to any economic shock that is worth seeing. However, it is also important to consider that Kuwait has a more volatile market, as it will help to better understand the dynamics of the local stock market. Another way to track market volatility is to look at frequent stock market movements (Barnes, 2017). To comprehend potentially unstable variance, a well-equipped Autoregressive Conditionally Heteroscedasticity (ARCH) and Generalized Autoregressive Conditional Heteroscedasticity (GARCH) models are implemented to explain gradual increments invariance over time. Autoregressive Conditional Heteroscedasticity (ARCH) models have commonly applied models coming into the field as these methods are known as autoregressive in square returns and the volatility of the following period depends on information from that period in these models. To understand these types of models, there are two sections (Agung, 2009).

The $I^{\text {st }}$ component is known as the conditional mean, which is equivalent to a traditional equation of regression. The $2^{\text {nd }}$ part known as the conditional variance formula, where the focus is on modeling the mean equation's time-reliant variance. Information for which the variances of the residual terms are not equal, and that the residual terms can rationally be predicted to be greater for some points or information ranges than for others, is considered to be heteroscedastic (Paul, 2007). A normal linear regression, i.e. $y_{i}=\alpha+\beta x_{i}+\varepsilon_{i}$ where the residual variance, i.e., is constant, is said to be homoscedastic and the ordinary least square method for estimating $\alpha$ and $\beta$ is applied in such a system.

Let us consider that the return on an asset is given as:

$r_{t}=\mu+\sigma_{t} \epsilon_{t}$

Where $\epsilon_{t}$ is a sequence of $\mathrm{N}(0, \mathrm{I})$ i.i.d. random variables. Then, we determine the residual return at time $t, r t-\mu$, as:

$$
\alpha_{t}=\sigma_{t} \epsilon_{t}
$$

In an $\mathrm{ARCH}(\mathrm{I})$ model, which was first developed by Engle (I982), we have that:

$\sigma_{t}^{2}=\alpha_{0}+\alpha_{1+} \alpha_{t-1}^{2}$

Where $\alpha 0>0$ and $\alpha_{I} \geq O$ have a positive variance and $\alpha \mathrm{I}<\mathrm{I}$ has a stationary variance. For an ARCH(I) model, if the residual return $\alpha_{t}$ is high in magnitude, the forecast for the conditional volatility of the next cycle will be large. Therefore, the derived returns are provisionally normal (provisional to all data up to $\mathrm{t}-\mathrm{I}$, the one-time normally distributed returns) and this condition can be relaxed under normality assumption. It is also important to note that the returns, $r$, are not correlated but not i.i.d.

Therefore, it is not difficult to detect a time-varying $\sigma_{t}^{2}$ outcomes in big tails in the unconditional distribution of $\alpha_{t}$ as opposed to a normal distribution (Campbell et al., I997).

The $\alpha_{t}$ kurtosis description is given as:

$$
\operatorname{kurt}\left(\alpha_{t}\right)=\frac{E\left[\alpha_{t}^{4}\right]}{\left(E\left[\alpha_{t}^{2}\right]\right)^{2}}
$$

If $\alpha_{t}$ considered as normally distributed and it is around 3. In such an occurrence, we have that:

$$
\operatorname{kurt}\left(\alpha_{t}\right)=\frac{E\left[\sigma_{t}^{4}\right] E\left[\epsilon_{t}^{2}\right]}{\left(E\left[\sigma_{t}^{2}\right)^{2}\left(E\left[\epsilon_{t}^{2}\right]\right)^{2}\right.}
$$

Furthermore, from Jensen's inequality (for a convex function, $f(x), E[f(x)]>f(E[x])$ ), we have that $E\left[\sigma_{t}^{4}\right]>$ $\left(E\left[\sigma_{t}^{2}\right]\right)^{2}$. Hence, $\operatorname{kurt}\left(\alpha_{t}\right)>3$.

An additional ratifying way for these models with time-varying $\sigma_{t}$ outcome in big tails is to ruminate models as a combination of normal variance. In specific, this investigation reveals some attributes of an $\mathrm{ARCH}(\mathrm{I})$ model. The $\alpha_{t}$ is specified as; 


$$
\begin{aligned}
\operatorname{Var}\left(\alpha_{t}\right) & =E\left[\alpha_{t}^{2}\right]-\left(E\left[\alpha_{t}\right]\right)^{2} \\
& =E\left[\alpha_{t}^{2}\right] \\
& =E\left[\sigma_{t}^{2} \epsilon_{t}^{2}\right] \\
& =E\left[\sigma_{t}^{2}\right] \\
& =\alpha_{0}+\alpha_{1} E\left[\alpha_{t-1}^{2}\right]
\end{aligned}
$$

And since $\alpha_{1}$ is a stationary process, $\operatorname{Var}\left(\alpha_{1}\right)=\operatorname{Var}\left(\alpha_{1}-\mathrm{I}\right)=E\left[\alpha_{t-1}^{2}\right]$

Thus, $\operatorname{Var}\left(\alpha_{1}\right)=\frac{\alpha_{0}}{1-\alpha_{1}}$

We indicate here that an ARCH (I) is akin to an AR (I) equation on squared errors, $\alpha_{t}^{2}$. This can be reviewed in the description of the forecast error (conditional), or the dissimilarity, between residual return (squared) and squared residual return (conditional expectation), given as:

$$
\begin{aligned}
v_{t} & =\alpha_{t}^{2}-E\left[\alpha_{t}^{2} \mid I_{t-1}\right] \\
& =\alpha_{t}^{2}-\sigma_{t}^{2}
\end{aligned}
$$

Where $I_{t-I}$ is the evidence at time $t-I$ and $v_{t}$ stand as an uncorrelated zero-mean series. The ARCH (I) equation develops as follows:

$$
\begin{aligned}
& \alpha_{t}^{2}=\alpha_{0}+\alpha_{1} \alpha_{t-1}^{2} \\
& \alpha_{t}^{2}-v_{t}=\alpha_{0}+\alpha_{1} \alpha_{t-1}^{2} \\
& \cdot \\
& \cdot \\
& \alpha_{t}^{2}=\alpha_{0}+\alpha_{1} \alpha_{t-1}^{2}+v_{t}
\end{aligned}
$$

This is an AR (I) method for squared residuals. The existing study is established on daily frequency-based stock returns (financial data), so an $\mathrm{ARCH}$ would give deep prudence in analyzing the nexus of Brent oil returns and stock returns. Over the past two decades, the ARCH family of parametric nonlinear time series models was developed to specifically address volatility data trends (Paul, 2007).

\subsection{Generalized Autoregressive Conditional Heteroscedasticity (GARCH)}

Generalized models of Autoregressive Conditional Heteroskedasticity (GARCH) help locate financial markets where patterns of volatility may change. It suggests that the behavior of returns becomes more unsettled in periods of international instability, financial crises or conflict, economic uncertainty, etc., and has a lower level of volatility in times of relative calm and stable economic era. The following equations outline the typical GARCH model $S R y_{i, t}=c_{0}+\sum_{i-1}^{m} a_{i} S R x_{t-i}+\varepsilon_{y t}$

Where $S R_{x}$ is the stock return of asset $\mathrm{X}$ and $S R_{y}$ is the stock return of asset $\mathrm{Y}$ and the serially correlated errors $\varepsilon_{y t}$ is termed by a Moving Average (I) process, which is given as:

$\varepsilon_{y t}=\mu_{y t}-\theta \mu_{y t-1}$

In this analysis, the typical GARCH model is modified to introduce volatility in stock returns. For GARCH models, which require robust $\mathrm{t}$-statistics from the Bollerslev-Wooldridge and the Jarque-Bera test for normality, residual diagnostic methods are performed. The statistics of the Ljung-Box (LB) help detect if there are any residual linear or nonlinear LB statistics and dependencies in the error terms that are calculated for the given equations because these statistics help to determine whether to accept the assumption of constant correlation overtime. If the specification of the variance equation is done correctly, then no ARCH should be found in the standardized residuals. 


\subsection{Diagnostic Tests}

Specific diagnostic tests are an important step towards modeling the time series. A list of the different residual diagnostic techniques used in the current study to verify the stability of the model and analysis. Such measures are discussed as follows. The residual test of the correlogram has used to evaluate the residual serial correlation. Jarque Bera has used to check residual normality and finally, the LM method applied to verify the ARCH effect.

\section{Empirical Findings}

Figure I shows a persistent rise in Brent oil prices (BP) was experienced until the beginning of 20I5. This is a situation that could be justified by the uncertainty over the side of oil supply related to the Arab Spring in 201 I abetted prices of oil return to preceding prices and levels stayed steady over three years (Bchir \& Pedrosa-Gorcia, 2015). Afterward, the graph shows the price started to display a downward trend until the end of 2017. Crude oil prices ended in 2015 under $\$ 40$ per barrel, the lowest level since early 2009, spot prices for global crude petroleum benchmarks Brent averaged \$52 per barrel in 2015 , 53 percent below 2014 level and 49\% below 2010-2014 spot prices. This reduction in oil prices reflects the continued surplus of supply of crude oil over global demand. As a result, global inventories of crude oil and other liquids are steadily increasing throughout the year, according to the 2016 report by the US Energy Information Administration.

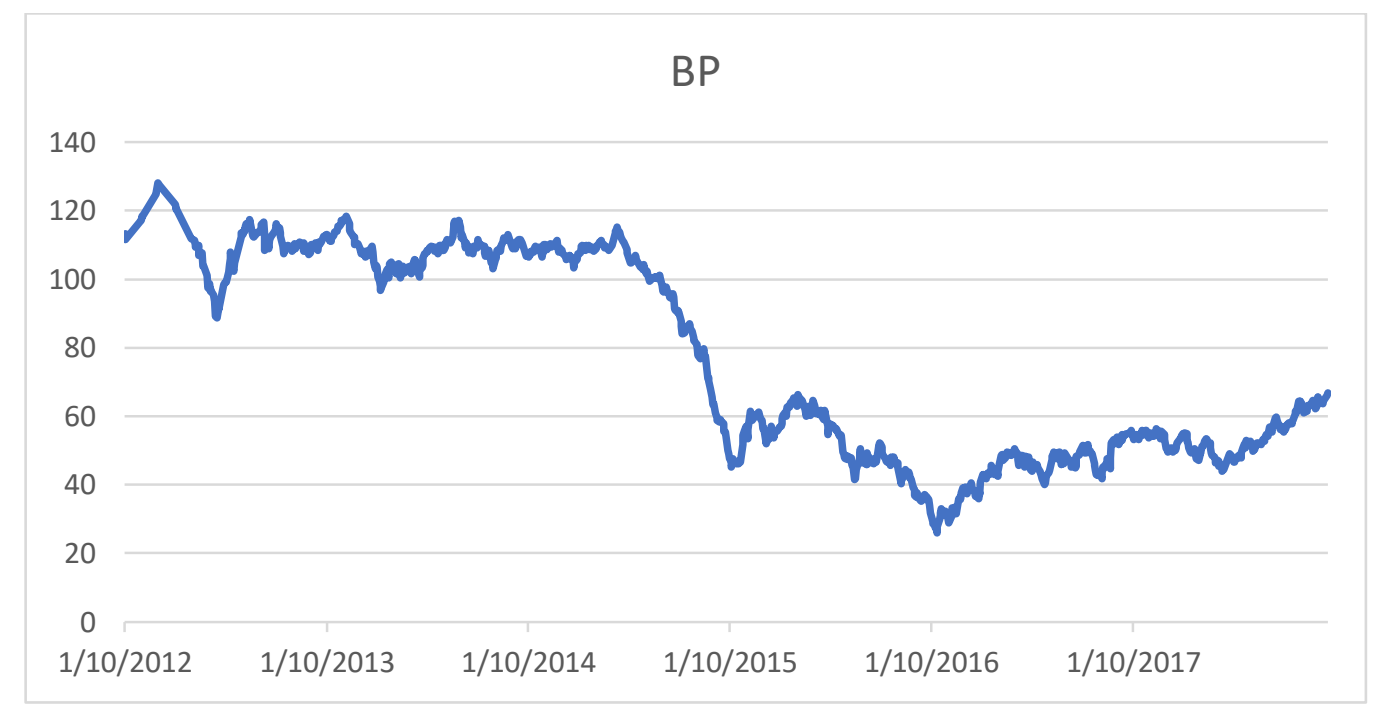

Figure I. Brent prices

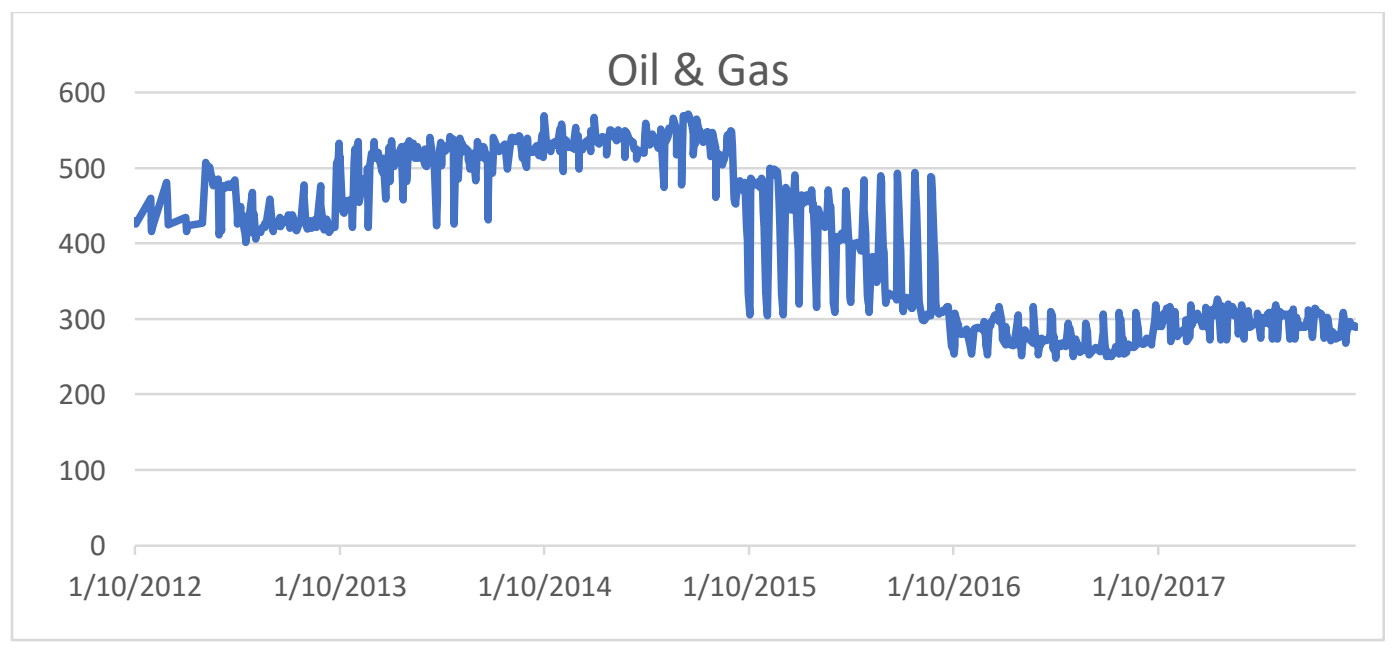

Figure 2. Oil and Gas sector stock prices 


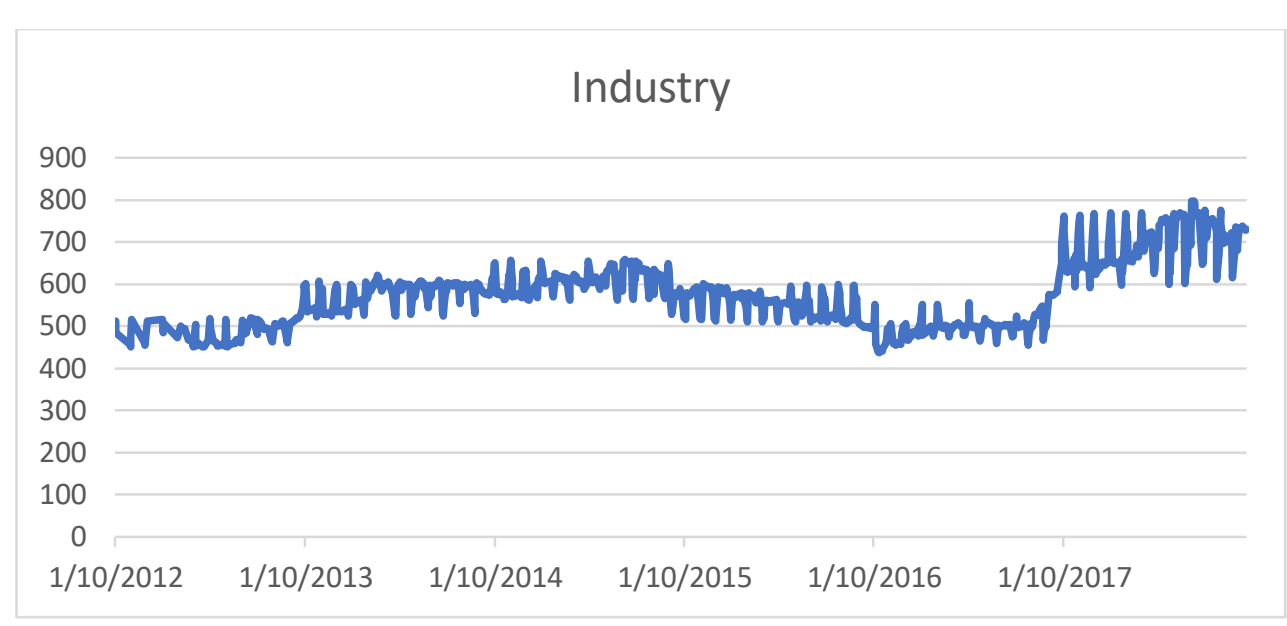

Figure 3. Industry sector stock prices

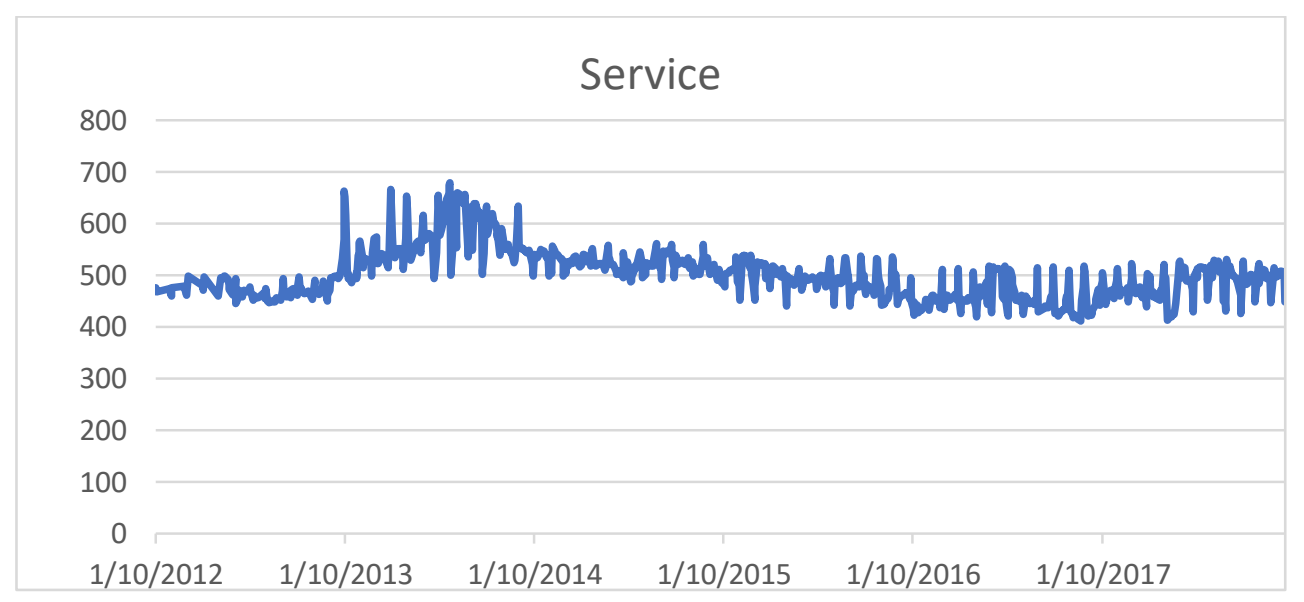

Figure 4. Services sector stock prices

In Figure 2 stock prices for oil and gas show a small upward trend in late 2012, which lasted until mid-20I5, trailed by a steady decline for the remaining sample period. All of these fluctuations are linked to significant levels of volatility-related to each of the events that influence market performance over time. It can be found that the phenomenon is the same in both cases when contrasting stock prices with oil prices. Uncertainty over the supply side of the Arab Spring Revolution has allowed oil prices to remain stable for more than three years to return to previous levels and prices (Bchir \& Pedrosa-Gorcia, 20I5).

In Figure 3, Industry stock prices had a steady movement from 2012 until mid-2017 and an upward movement was observed after mid-2017. The industrial segment was the main sponsor for income growth in 20I6. Profit for this sector was I8I million KD, up 49\%, this increase was mainly due to setbacks in a large loss experienced in 2015 by one of the corporations (Kuwait Economic Brief, 2017). Figure 4 indicates that the service's stock price had a consistent downward trend after 2014. One of the sectors was primarily behind this drop, also several companies in the sector witnessed a decline in profit during all periods (Kuwait Economic Brief, 2017).

TableI. Descriptive statistics

\begin{tabular}{|c|c|c|c|c|c|c|}
\hline \multirow[t]{2}{*}{ Variables } & \multicolumn{6}{|c|}{ Descriptive Statistics } \\
\hline & Mean & $\mathrm{SD}$ & SK & $\mathrm{KT}$ & $\mathrm{JB}$ & Obs \\
\hline $\mathrm{BP}$ & 74.9450 & 29.0615 & 0.19892 & $\mathrm{I} .3236$ & 128.0093 & 1035 \\
\hline $\mathrm{O} \& \mathrm{G}(\mathrm{SP})$ & 404.7674 & $\mathrm{I06.003}$ & -0.0243 & $\mathrm{I} .3698$ & $\mathrm{II} 4.7025$ & 1035 \\
\hline Ind (SP) & 575.0955 & 78.0578 & 0.6403 & 2.9832 & 70.7554 & 1035 \\
\hline
\end{tabular}




\begin{tabular}{lllllll}
\hline Ser (SP) & $500.387 \mathrm{I}$ & 47.7866 & 0.92633 & 4.4076 & 233.474 & $\mathrm{I035}$ \\
\hline BPR (Returns) & -0.0005 & 0.0238 & 0.1413 & 6.6259 & 569.875 & $\mathrm{I034}$ \\
\hline O\&G(Returns) & -0.0003 & $0.067 \mathrm{I}$ & 2.1004 & $\mathrm{I} 8.089$ & $\mathrm{I0570.19}$ & $\mathrm{I034}$ \\
\hline Ind (Returns) & .000343 & .04388 & -.372672 & 8.2687 & $\mathrm{I} 2 \mathrm{I9} .907$ & $\mathrm{I034}$ \\
\hline Ser (Returns) & $-5.79 \mathrm{E}-05$ & 0.0454 & -0.15950 & 9.7453 & $\mathrm{I} 964.642$ & $\mathrm{I} 034$ \\
\hline
\end{tabular}

BP: Brent Prices, O \& G: Oil \& Gas Stock Prices, Ind: industry stock prices, Ser: Services stock prices. BPR: Brent returns, O \& GR: Oil \& Gas return, India: Industry return, SerR: Services return.

Table I provides descriptive statistics for sector indexes. The SD for all explanatory predictors varies from 0.0238 to 106.003. The minimum standard deviation i.e. 0.0238 stands for Brent returns, which means that it has a lesser difference, and on the other hand, $\mathrm{O} \& \mathrm{G}$ (SP) has the highest SD of 106.003, which indicates a high level of variation. Significantly, the industrial mean value is high for all periods under study, and Brent return has the lowest mean. Skewness is noted that the value for all predictors is near zero excluding in the case of oil and gas returns, where it changes from an inverse one to a positive two. The coefficient of both Kurtosis and skewness (lower than 3) reveals that Brent prices and stock prices showing a platykurtic trend. Also, the values of the Jarque-Bera method are high for all predictors indicating that the series are non-normal.

Table 2. Pooled Outputs

\begin{tabular}{|c|c|c|c|c|c|c|c|c|c|c|}
\hline \multirow{3}{*}{ Sectors } & \multirow[t]{3}{*}{ Lags } & \multirow{3}{*}{$\begin{array}{l}\text { Unit } \\
\text { Root }\end{array}$} & \multicolumn{4}{|c|}{ Cointegration } & \multirow{2}{*}{\multicolumn{2}{|c|}{ Granger Causality }} & & \multirow[t]{2}{*}{$\overline{\operatorname{GARCH}}(\mathrm{I}, \mathrm{I})$} \\
\hline & & & EG & & $\pi$ & & & & & \\
\hline & & & $\mathrm{BP}$ & $\mathrm{SP}$ & $\mathrm{BP}$ & $\mathrm{SP}$ & $\mathrm{BPR} \rightarrow \mathrm{SPR}$ & $\begin{array}{l}\text { SPR } \\
\text { BPR }\end{array}$ & $\rightarrow$ & $\alpha+\beta$ \\
\hline $\begin{array}{ll}\text { Oil } \quad \& \\
\text { Gas }\end{array}$ & $\mathrm{I}$ & $\mathrm{I}(\mathrm{I})$ & 0.5217 & 0.76 & $0.000 I^{*}$ & $0.0900^{2 x}$ & $0.4 \mathrm{II} 4$ & 0.6793 & & 0.998146 \\
\hline Industry & $\bar{I}$ & $\mathrm{I}(\mathrm{I})$ & 0.8244 & 0.9632 & 0.2268 & 0.1212 & 0.4237 & 0.3274 & & 0.99806 \\
\hline Service & $\bar{I}$ & $\mathrm{I}(\mathrm{I})$ & 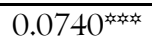 & $0.3 \mathrm{I} 6 \mathrm{I}$ & $0.000^{\text {多 }}$ & 0.1255 & 0.2203 & 0.7880 & & 0.998034 \\
\hline
\end{tabular}

The result from the SIC method as shown in Table 2 demonstrates that the ideal number of lags is equal to one for all variables. The core idea of the estimation of these lags is to safeguard that the econometric equation is correctly accessible to minimize potential problems related to the model's misrepresentation. The model estimates will lead to spurious research results in the case of incorrect lag selection. A very minor lag length becomes a reason of autocorrelation that can lead to bungling estimators and, on the other side, a long lag length increases the size of the parameter, which decreases the degrees of freedom and consequences in huge standard errors and confidence intervals for the model's coefficients and the time that the model could not properly capture the dynamic variables (Füss, 2007). The second step is an Augmented Dicky Fuller (ADF) stationary test. The results indicate that the variables at levels are non-stationary, meaning that the first difference in the data is implemented and the ADF test applied again. In response to this step, all variables underneath are now a one-order $\mathrm{I}(\mathrm{I})$ integrated process, revealing that all series are stationary in the same order. The study used the Phillips-Perron (PP) and Kwiatkowski-PhillipsSchmidt-Shin (KPSS) tests to test for robustness. The findings of PP and KPSS approaches are fully consistent with ADF.

Research results indicate no substantial evidence to improve the presence of a long-term connection between the stock and Brent prices excluding in the oil and gas sector where the Johanson test revealed a long-term linkage, but the Engle-Granger technique does not support this result because the results of the Johansen outcomes are in line with the Engle-Granger methodology based on a two-step format of estimation. The first stage is to produce the residuals and the second phase uses the residuals produced to approximate a regression of first-differentiated residuals on lagged residuals. Any mistake that happens in the first step will, therefore, be passed to the second step. In the Johansen cointegration test, however, this does not happen, and as such, the Johansen method is more powerful in conflict situations between the EG and the Johansen technique (Billgili, 1998). These results point to the general lack of a long-term equilibrium between oil and stock prices in Kuwait, which means that information contained in oil prices does not help predict future stock price movements and vice versa (Arouri \& Fouquau, 2009; Zarour, 2006; Hammoudeh \& Aleisa, 2004).

The causality test was used to detect whether Brent returns have a short-run impact on stock returns in the sector and vice versa. This experiment was used to demonstrate whether the returns from Brent could be a justification for a shift in stock returns as the Kuwaiti stock exchange market is highly sensitive to variations in oil prices. The result shows no evidence of (c) (1) \& Copyright (C) CC-BY-NC 2020, CRIBFB | IJAFR 39 
unidirectional causality between returns from Brent and returns from stocks. Liquidity is an up-and-down financial market activity, and as such, liquidity in financial markets is considered an important factor. Volatility raises during times of uncertainty, the biggest driver of volatility being the likelihood of a drop in market prices. Volatility remains a significant tool for considerate market risk, as truncated levels of volatility are generally associated with stable or predictable conditions. Another way to observe low market volatility is to look at daily stock market changes (Barnes, 2017). The main outcome of the GARCH $(\mathrm{I}, \mathrm{I})$ model shows stability in all sectors as the summation of alpha and beta measurements is less than one.

\section{Conclusions}

This research aimed to test the effect of Brent prices overstock prices for the three different sectors in the Kuwait stock exchange market, gas and oil, industry and the services. The study is well maintained by a mixture of econometric models that helped to inspect the association between the particular sectors and oil prices. The general results reveal that there exist no long-run linkages between Brent and stock prices across all sectors except in the case of the oil and gas sector. These outcomes show that the effect of oil prices seems irrelevant to forecast prices of stocks. The results of the Granger causality method directs a lack of unidirectional causality running from Brent to the sectors and vice versa. The GARCH model is stable for all sectors and the residual diagnostic tests illustrate the favorable outcomes of all sectors under study.

\section{References}

Abdelaziz, M., Chortareas, G., \& Cipollini, A. (2008). Stock prices, exchange rates, and oil: Evidences from Middle East oilexporting countries. Topics in Middle Eastern and North African Economies, IO.

Adrangi, B., Chatrath, A., \& Raffiee, K. (20I4). Volatility spillovers across major equity markets of Americas. International journal of business, I9(3), 255-274.

Agung, I. (2009). Time Series Data Analysis Using EViews. Singapore: John Wiley \& Sons.

Al-Qudsi, S., \& Ali, M. (2016). Economic Growth Implications of Oil Prices Fluctuations: The GCC Context. Doha Institute.

Ansani, A., \& Daniele, V. (2012). About a revolution: The economic motivations of the Arab Spring. International Joumal of Development and Conflict, 2(3), I250013-24.

Arezki, R., Ramey, V. A., \& Sheng, L. (2017). News shocks in open economies: Evidence from giant oil discoveries. The quarterly journal of economics, I32( I), I03-I55.

Arouri, M. E. H., \& Fouquau, J. (2009). How do oil prices affect stock returns in GCC markets? An asymmetric cointegration approach. Orleans Economic Laboratory, University of Orleans, Working Paper.

Asteriou, D., \& Bashmakova, Y. (2013). Assessing the impact of oil returns on emerging stock markets: A panel data approach for ten Central and Eastern European Countries. Energy Economics, 38, 204-2I I.

Azar, S. A., \& Basmajian, L. (2013). Oil prices and the Kuwaiti and the Saudi stock markets: The contrast. International Journal of Economics and Financial Issues, 3(2), 294-304.

Bahmani-Oskooee, M., \& Saha, S. (2015). On the relation between stock prices and exchange rates: a review article. Journal of Economic Studies, 42(4), 707-732.

Barnes, I. (2017). Managing market volatility. Retrieved from http://www.cityam.com/26679I/managing-stock-marketvolatility.

Bchir, M. H., \& Pedrosa-Garcia, J. A. (20I5). The impact of the 2014 oil shocks on Arab Economies. Chapter 3 in ESCWA's. Survey of Economics and Social Development in the Arab Region, 2014-2015.

Bilgili, F. (1998). Stationarity and cointegration tests: Comparison of Engle-Granger and Johansen methodologies. Erciyes Üniversitesi Íktisadi ve İdari Bilimler Fakültesi Dergisi, (I3), I3I-I4I.

Bouri, E., Awartani, B., \& Maghyereh, A. (2016). Crude oil prices and sectoral stock returns in Jordan around the Arab uprisings of 2010. Energy Economics, 56, 205-214.

Breitung, J., \& Candelon, B. (2006). Testing for short-and long-run causality: A frequency-domain approach. Journal of econometrics, I32(2), 363-378.

Campbell, J. Y., Champbell, J. J., Campbell, J. W., Lo, A. W., Lo, A. W., \& MacKinlay, A. C. (I997). The econometrics of financial markets. princeton University press.

Chau, F., Deesomsak, R., \& Wang, J. (20I4). Political uncertainty and stock market volatility in the Middle East and North African (MENA) countries. Journal of International Financial Markets, Institutions and Money, 28, I-I9.

Constantinos, K., Ektor, L. A., \& Dimitrios, M. (2010). Oil price and stock market linkages in a small and oil dependent economy: The case of Greece. Journal of Applied Business Research (JABR), 26(4), 55-63.

Cunado, J., \& de Gracia, F. P. (20I4). Oil price shocks and stock market returns: Evidence for some European countries. Energy Economics, 42, 365-377.

Engle, R. F., \& Granger, C. W. (I987). Co-integration and error correction: representation, estimation, and testing. Econometrica: Journal of the Econometric Society, 55(2), 25I-276. 
Engle, R. (1982). Dynamic conditional correlation: A simple class of multivariate generalized autoregressive conditional heteroskedasticity models. Journal of Business \& Economic Statistics, 20(3), 339-350.

Ferderer, J. P. (1996). Oil price volatility and the macroeconomy. Journal of macroeconomics, I8(I), I-26.

Filis, G., Degiannakis, S., \& Floros, C. (20II). Dynamic correlation between stock market and oil prices: The case of oilimporting and oil-exporting countries. International Review of Financial Analysis, 20(3), I52-I64.

Füss, R. (2007). Chapter 4: Vector autoregressive models. Uni Freiburg, viewed 28. May 20I I. URL http://www. empiwifo. uni-freiburg. de/lehre-teaching-I/winter-term/dateien-financial-dataanalysis/chapter4. pdf [accessed 28 May 2011 ].

Geweke, J. (1982). Measurement of linear dependence and feedback between multiple time series. Journal of the American statistical association, $77(378), 304-313$.

Granger, C. W., Huangb, B. N., \& Yang, C. W. (2000). A bivariate causality between stock prices and exchange rates: evidence from recent Asianflus?. The Quarterly Review of Economics and Finance, 4O(3), 337-354.

Grima, S., \& Caruana, L. (2017). The Effect of the Financial Crisis on Emerging Markets. A comparative analysis of the stock market situation before and after. In DIEM: Dubrovnik International Economic Meeting, 3( I), 228-254.

Guesmi, K., Abid, I., Creti, A., \& Chevallier, J. (2018). Oil price risk and financial contagion. The Energy Journal, 39(2), 97II5.

Hammoudeh, S., \& Aleisa, E. (2004). Dynamic relationships among GCC stock markets and NYMEX oil futures. Contemporary Economic Policy, 22(2), 250-269.

Hosoya, Y. (I99I). The decomposition and measurement of the interdependency between second-order stationary processes. Probability theory and related fields, 88(4), 429-444.

Ibbotson, R. (20I I). Why does market volatility matter. Yale School of Management, Yale School of Management.

Imarhiagbe, S. (2010). Impact Of Oil Prices On Stock Markets: Empirical Evidence From Selected Major Oil Producing And Consuming Countries. Global Journal of Finance \& Banking Issues, 4(4), I-I7.

Ivanov, V., \& Kilian, L. (2005). A practitioner's guide to lag order selection for VAR impulse response analysis. Studies in Nonlinear Dynamics \& Econometrics, 9(I), I-36.

Jiang, Y., Yu, M., \& Hashmi, S. M. (2017). The financial crisis and co-movement of global stock markets-A case of six major economies. Sustainability, $9(2), 260$.

Johansen, S. (1988). Statistical analysis of cointegration vectors. Journal of economic dynamics and control, I2(2-3), 23 I-254.

Kilian, L. (2009). Not all oil price shocks are alike: Disentangling demand and supply shocks in the crude oil market. American Economic Review, $99(3)$, I053-69.

Kumar, D., \& Maheswaran, S. (2013). Correlation transmission between crude oil and Indian markets. South Asian Journal of Global Business Research, 2(2), 2 I I-229.

Kuwait Economic Brief. (2017). Retrieved from at https://www.nbk.com « dam r NBK. Kuwait Economic Brief.

Miller, J. I., \& Ratti, R. A. (2009). Crude oil and stock markets: Stability, instability, and bubbles. Energy Economics, 3I(4), 559-568.

Muhtaseb, B. M., \& Al-Assaf, G. (2017). Oil price fluctuations and their impact on stock market returns in Jordan: Evidence from an asymmetric cointegration analysis. International Journal of Financial Research, 8(I), I72-I80.

Narayan, P. K., \& Sharma, S. S. (20I4). Firm return volatility and economic gains: the role of oil prices. Economic Modelling, 38, I42-I5I.

Narayan, P. K., \& Gupta, R. (2015). Has oil price predicted stock returns for over a century?. Energy Economics, 48, I8-23.

Paul, R. K. (2007). Autoregressive conditional heteroscedastic (ARCH) family of models for describing volatility. In Seminar Paper. Indian Agricultural Statistics Research Institute.

Zarour, B. A. (2006). Wild oil prices, but brave stock markets! The case of GCC stock markets. Operational Research, 6(2), I45-I62.

\section{Copyrights}

Copyright for this article is retained by the author(s), with first publication rights granted to the journal. This is an open-access article distributed under the terms and conditions of the Creative Commons Attribution license (http://creativecommons.org/licenses/by/4.0/). 